Evaluation of the Emission, Transport, and Deposition of Mercury, Fine Particulate Matter, and Arsenic from CoalBased Power Plants in the Ohio River Valley Region

\author{
Semi-Annual Technical Progress Report \\ for the Period April 3, 2003-October 2,2003 \\ to \\ Department of Energy \\ Washington, D.C. \\ DOE Award Number: DE-FC26-03NT41723
}

Award Recipient:

Ohio University

Athens, Ohio 
Report Period Start Date:

Report End Date:

Principal Author:

DOE Award Number:

Contractor:

Subcontractors:
April 3, 2003

October 2, 2003

Kevin Crist

Ohio University

DE-FC26-03NT41723

\section{Ohio University}

Institute for Sustainable Energy and the Environment Building 21, The Ridges

Athens Ohio, 45701

CONSOL Energy

Research \& Development

400 Brownsville Road

South Park, PA 15129-9566

Advanced Technology Systems, Inc.

639 Alpha Drive-RIDC Park

Pittsburgh, PA 15238-2819

Atmospheric and Environmental Research, Inc.

131 Hartwell Avenue

Lexington, MA 02421-3126

\section{DISCLAIMER}

This report was prepared as an account of work sponsored by an agency of the United States Government. Neither the United States Government nor any agency thereof, nor any of their employees, makes warranty, express or implied, or assumed any legal liability or responsibility for the accuracy, completeness, or usefulness of any information, apparatus, product, or process disclosed, or represents that its use would not infringe privately owned rights. Reference herein to any specific commercial product process, or service by trade name, trademark, manufacturer, or otherwise does not necessarily constitute or imply its endorsement, recommendation, or favoring by the United States Government or any agency thereof. The views and opinions of authors expressed herein do not necessarily state or reflect those of the United States Government or any agency thereof. 


\section{TABLE OF CONTENTS}

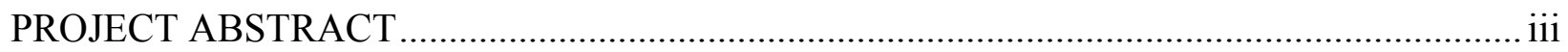

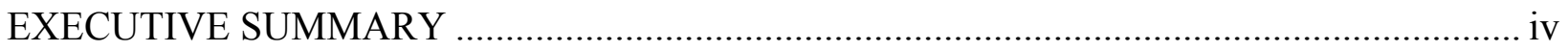

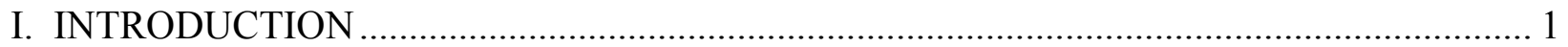

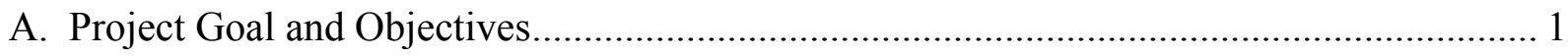

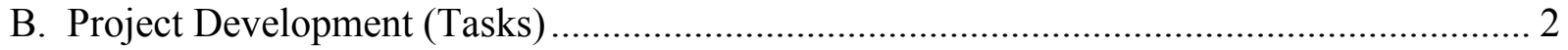

II. EXPERIMENTAL DESIGN .................................................................................... 3

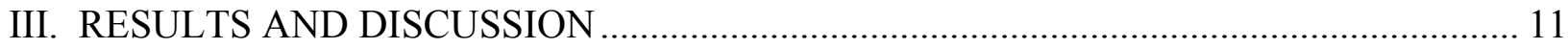

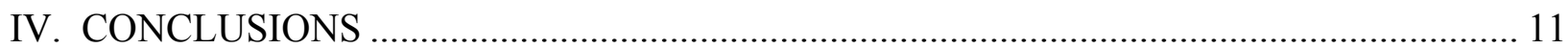

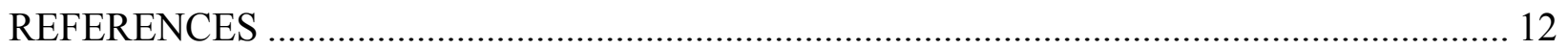

\section{LIST OF TABLES}

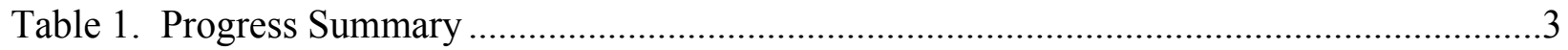

\section{LIST OF FIGURES}

Figure 1. Topographical map of the Athens site........................................................... 4 


\section{PROJECT ABSTRACT}

Ohio University, in collaboration with CONSOL Energy, Advanced Technology Systems, Inc (ATS) and Atmospheric and Environmental Research, Inc. (AER) as subcontractors, is evaluating the impact of emissions from coal-fired power plants in the Ohio River Valley region as they relate to the transport and deposition of mercury, arsenic, and associated fine particulate matter. This evaluation will involve two interrelated areas of effort: ambient air monitoring and regional-scale modeling analysis.

The scope of work for the ambient air monitoring will include the deployment of a surface air monitoring (SAM) station in southeastern Ohio. The SAM station will contain sampling equipment to collect and measure mercury (including speciated forms of mercury and wet and dry deposited mercury), arsenic, particulate matter (PM) mass, PM composition, and gaseous criteria pollutants $\left(\mathrm{CO}, \mathrm{NOx}, \mathrm{SO}_{2}, \mathrm{O}_{3}\right.$, etc.). Laboratory analysis of time-integrated samples will be used to obtain chemical speciation of ambient PM composition and mercury in precipitation. Near-real-time measurements will be used to measure the ambient concentrations of PM mass and all gaseous species including $\mathrm{Hg}^{0}$ and RGM. Approximately of 18 months of field data will be collected at the SAM site to validate the proposed regional model simulations for episodic and seasonal model runs. The ambient air quality data will also provide mercury, arsenic, and fine particulate matter data that can be used by Ohio Valley industries to assess performance on multi-pollutant control systems.

The scope of work for the modeling analysis will include (1) development of updated inventories of mercury and arsenic emissions from coal plants and other important sources in the modeled domain; (2) adapting an existing 3-D atmospheric chemical transport model to incorporate recent advancements in the understanding of mercury transformations in the atmosphere; (3) analyses of the flux of $\mathrm{Hg} 0, \mathrm{RGM}$, arsenic, and fine particulate matter in the different sectors of the study region to identify key transport mechanisms; (4) comparison of cross correlations between species from the model results to observations in order to evaluate characteristics of specific air masses associated with long-range transport from a specified source region; and (5) evaluation of the sensitivity of these correlations to emissions from regions along the transport path. This will be accomplished by multiple model runs with emissions simulations switched on and off from the various source regions.

To the greatest extent possible, model results will also be compared to field data collected at other air monitoring sites in the Ohio Valley Region, operated independently of this project. These sites may include (1) the DOE National Energy Technologies Laboratory's monitoring site at its suburban Pittsburgh, PA facility; (2) sites in Pittsburgh (Lawrenceville) PA and Holbrook, PA operated by ATS; (3) sites in Steubenville, OH and Pittsburgh, PA operated by U.S. EPA and/or its contractors; and (4) sites operated by State or local air regulatory agencies. Field verification of model results and predictions will provide critical information for the development of cost effective air pollution control strategies by the coal-fired power plants in the Ohio River Valley Region. 


\section{EXECUTIVE SUMMARY}

Ohio University is performing a Cooperative Agreement with the U.S. Department of Energy's National Energy Technology Laboratory (DOE-NETL) to conduct regional-scale modeling analysis and ambient air monitoring that will provide critical information for the development of relevant and cost effective control strategies by the coal-fired power plants in the Ohio River Valley Region.

The regional modeling studies will develop a comprehensive budget of arsenic, elemental mercury $\left(\mathrm{Hg}^{0}\right)$ reactive gaseous mercury (RGM), and fine particulate matter across the Ohio Valley Region, including sources, sinks, atmospheric lifetimes, burdens, and advective fluxes. Updated emissions inventories for mercury and arsenic within the region will be developed to support the regional modeling studies. A comprehensive surface air monitoring (SAM) site is being developed and operated in southeastern Ohio to provide field data against which the model results can be compared. The SAM has the capability to monitor mercury speciation in ambient air and in precipitation, and it contains a full range of instrumentation for measuring the composition of fine particulate matter and co-pollutant gases. Short-term and seasonal simulations with the refined model will be compared to field measurements from the monitoring site, and the results will be used to develop a decision-support tool. A supplemental objective of the analysis is to evaluate the impacts of long-range transport from regions outside the Ohio Valley as well as biospheric recycling of elemental $\mathrm{Hg}$ on the measured and modeled reactive and total mercury concentration levels in the Ohio Valley Region.

The Cooperative Agreement began in April of 2003; work will take place over a 27-month performance period, ending in June 2005. The effort has been broken down into seven separate tasks as follows:

Task 1 consists of establishing and operating the SAM site in southeastern Ohio. It is anticipated that approximately 6 months will be required before the SAM site is completely set up and operational; data collection will occur over the following 18 months.

Task 2 consists of the selection and evaluation of a 3-D regional-scale chemical transport model (CTM) for an application focused on the Ohio River Valley Region. It is anticipated that the setup of the CTM and development of its grid system will be completed within the first 5 months of the project. In addition, a one-year base-case simulation will be conducted for North America. This simulation will be completed by the end of the first year of the project.

Task 3 involves the refinement and update of emission inventories (EIs) for sources of mercury and arsenic within and upwind of the modeled domain. The Institute for Sustainable Energy and the Environment (ISEE) plans to collect and process that emissions information into the model structure throughout the modeling effort.

Task 4 consists of short-period model runs to be made for comparison with field data. It is anticipated that the summer of 2001 will be used for initial comparisons because of the vast amount of field data on particulate matter that is likely to be available for the Ohio River valley region during that time. Short-term model runs for comparison with the speciated mercury and arsenic data collected at the SAM for the 2002 and 2003 sampling periods will follow the initial comparisons. During the third month of the project, researchers will begin meteorological 
simulations for the short-term model runs and continue them intermittently for approximately 15 months.

Task 5 involves seasonal-scale simulations that focus on the identification of significant sources and source regions contributing to the deposition of mercury and ambient concentrations of arsenic and fine particulate matter over periods of several months or more. The modeling will also examine the efficacy of emission reduction strategies specifically for coal-fired power plants. In addition, researchers will conduct an analysis of long-range transport from regions outside the Ohio Valley and biospheric recycling of elemental $\mathrm{Hg}$ on the measured and modeled reactive and total mercury in the Ohio Valley Region.

Task 6 consists of the development of Web-based model interface technologies to provide industry and government agencies with a user-friendly decision-support tool to facilitate the evaluation of source-receptor relationships and the efficacy of emission reduction strategies.

Task 7 consists of project management, data analysis, and reporting functions.

Accomplishments and tasks completed during this reporting period include (1) selecting and adapting a 3-D regional chemical transport model for the evaluation of ambient mercury, arsenic and associated $\mathrm{PM}_{2.5}$; (2) refining and updating existing emissions inventories to include mercury and arsenic emissions; (3) developing the framework for parallel simulations to conduct shortperiod model runs for comparison with field data; (4) establishing a surface air monitoring station (SAM) at Athens, Ohio to include sampling equipment for collecting and measuring mercury, arsenic, $\mathrm{PM}_{2.5}$, pollutant gases, and weather data over the project period; and (5) presenting an overview of the project to key stakeholders. 


\section{INTRODUCTION}

Ohio University is performing a Cooperative Agreement with the U.S. Department of Energy's National Energy Technology Laboratory (DOE-NETL) to conduct regional-scale modeling analysis and ambient air monitoring that will provide critical information for the development of relevant and cost effective control strategies by the coal-fired power plants in the Ohio River Valley Region.

Coal flue gas contains a variety of hazardous air pollutants (HAPs), including organic and inorganic chemical compounds. Among the latter, the metals mercury and arsenic are of particular concern because of their toxicity to humans and animals. An understanding of the chemistry of these elements should be the basis of proposed legislation to regulate mercury and arsenic emissions since specific chemical species will account for differences in human toxicity, rate of transport through the ecosystem, and the design variations in possible emission control schemes. An additional layer of complexity results from the fact that these elements may or may not be associated with fine particulate matter $\left(\mathrm{PM}_{2.5}\right.$ and $\left.\mathrm{PM}_{10}\right)$ during or after emission from a stack. In general, the less volatile species such as arsenic and oxidized mercury are likely to be associated with fine particulate matter while the more volatile moieties such as elemental or reduced mercury tend to be emitted as non-associated gases. Thus, it will be necessary to determine the chemical forms of mercury and arsenic present at the stack and at designated receptor sites, and to determine the fractions of these species bound to fine particulate matter.

Mercury, fine particulate matter, and arsenic can be transported over large distances due to their minimal rate of sedimentation. In particular, mercury transport must be considered a global problem. Elemental mercury is believed to have a half-life of approximately one year in the atmosphere, and little is known about its cyclic transport between land, water, and air. Biogenic transport and biogenic sources are even less well understood. Therefore, the ISEE will adopt a regional scale approach for adequate evaluation of source-receptor relationships for mercury, fine particulate matter, and arsenic. Our approach in evaluating the impact of arsenic and mercury emissions from coal-fired power plants and other sources is to examine the sourcereceptor relationship through ambient monitoring and regional scale modeling.

\section{A. Project Goal and Objectives}

The overall objective of the project is to quantitatively evaluate the emission, transport, and deposition of mercury, fine particulate matter (PM), and air toxics (arsenic) in the Ohio River Valley Region. This evaluation involves two interrelated areas of effort: regional-scale modeling analysis and ambient air monitoring.

The objective of the regional modeling studies is to develop a comprehensive budget of arsenic, elemental mercury $\left(\mathrm{Hg}^{0}\right)$ and reactive gaseous mercury (RGM), and fine particulate matter including sources, sinks, atmospheric lifetimes, burdens, and advective fluxes across the Ohio Valley Region. To support this objective, project researchers will develop updated emissions inventories for mercury and arsenic within the region. The second objective is to develop an airmonitoring site in Athens, Ohio to provide the capability to monitor mercury in ambient air and in precipitation. Researchers will compare the refined model's short-term and seasonal simulations to field measurements from the monitoring site and use the results to develop a 
decision-support tool. A supplemental objective of the analysis is to evaluate the impacts of long-range transport from regions outside the Ohio Valley as well as biospheric recycling of elemental $\mathrm{Hg}$ on the measured and modeled reactive and total mercury concentration levels in the Ohio Valley Region.

\section{B. Project Development (Tasks)}

Seven separate tasks will be completed over a 27 -month performance period. The following project schedule is based on a project start date of April 3,2003. Table 1 on page 3 presents a progress summary for each task. Section II Experimental Design is a detailed description of each task and the progress achieved toward its completion as of September 30, 2003.

\section{Project Schedule}

- Task 1 consists of establishing and operating a Stationary Ambient Monitoring (SAM) site in Athens, Ohio. It is anticipated that approximately 6 months will be required before the SAM site is completely set up and operational; data collection will occur over the following 18 months.

Tasks 2-6 comprise the modeling process, which will continue throughout the first 24 months of the project. Throughout Tasks $2-6$, the project team will keep abreast of ongoing research and newly published literature pertaining to the atmospheric behavior of mercury. Whenever possible, new findings concerning mercury speciation and transport will be incorporated into the model algorithms.

- Task 2 consists of the selection and evaluation of a 3-D regional-scale chemical transport model (CTM) for an application focused on the Ohio River Valley Region. The project team anticipates the completion of the CTM setup and development of its grid system within the first 5 months of the project. In addition, a one-year base-case simulation will be conducted for North America. This simulation will be completed by the end of the first year of the project.

- Task 3 involves the refinement and update of emission inventories (EIs) for sources of mercury and arsenic within and upwind of the modeled domain. It is anticipated that information on emissions will continue to be collected and processed into the model structure throughout the modeling effort.

- Task 4 consists of conducting short-period model runs for comparison with field data. The project team plans to use data collected during the summer of 2001 for initial comparisons because of the vast amount of field data on particulate matter likely to be available for the Ohio River Valley Region during that period. Short-term model runs for comparison with the speciated mercury and arsenic data collected at the Athens SAM for the 2004 sampling periods will follow the initial comparisons. The team will begin meteorological simulations for the short-term model runs during the third month of the project, and they will schedule intermittent short-term model runs for approximately 15 months. 
- Task 5 involves seasonal-scale simulations that focus on the identification of significant sources and source regions contributing to the deposition of mercury and ambient concentrations of arsenic and fine particulate matter over periods of several months or more. The modeling will also examine the efficacy of emission reduction strategies specific to coalfired power plants. In addition, researchers will analyze the long-range transport from regions outside the Ohio Valley and the biospheric recycling of elemental $\mathrm{Hg}$ on the measured and modeled reactive and total mercury in the Ohio Valley Region.

- Task 6 will consist of the development of Web-based model interface technologies to provide industry and government agencies with a user-friendly decision-support tool to facilitate the evaluation of source-receptor relationships and the efficacy of emission reduction strategies.

- Task 7 consists of project management, data analysis, and reporting functions.

Table 1 below is a progress summary for each task.

Table 1. Progress Summary

\begin{tabular}{|c|l|c|c|}
\hline Task \# & \multicolumn{1}{|c|}{ Description } & $\begin{array}{c}\text { Planned \% } \\
\text { Completed }\end{array}$ & $\begin{array}{c}\text { Actual \% } \\
\text { Completed }\end{array}$ \\
\hline 1 & SAM & 22 & 10 \\
\hline 2 & Base Case Simulation & 100 & 10 \\
\hline 3 & Emission Inventories & 33 & 33 \\
\hline 4 & Model Comparison & 40 & 10 \\
\hline 5 & Seasonal Scale Simulations & 0 & 0 \\
\hline 6 & Development of Support Tool & 0 & 0 \\
\hline 7 & Project Management & 22 & 10 \\
\hline
\end{tabular}

\section{EXPERIMENTAL DESIGN}

In this section, the description of each task is presented as it was proposed in the funding application. Following the description is a discussion of the progress made toward completing the task.

$\underline{\text { Task } 1 \text { - Establish and operate a (SAM) station in Athens, Ohio }}$

The proposal for this project designated that the ISEE would establish a SAM station in Steubenville, Ohio. However, prior to April 3, 2003 the Environmental Protection Agency set up a SAM station in Steubenville that has the capacity to monitor for mercury. Consequently, the ISEE was able to select another site for the SAM station proposed for this project. The project staff located an optimal site south of Athens, Ohio in the heart of the Ohio River Valley. At an elevation of 950 feet, the site is the highest point within a 100-mile radius to the east, south, and west (Figure 1, page 4). It is an excellent site from which to capture the transport of pollutants into and out of the valley. In addition, a 350-foot communication tower is adjacent to the site. ISEE staff will install a wind-speed and wind-direction sensor atop the tower that will provide critical information for evaluating transport events. 
NOTE: Consol Energy R\&D is performing the majority of Task 1 under subcontract to Ohio University. The subcontract was not executed until August 5, 2003, which delayed Task 1 by several months.

(a) Regional

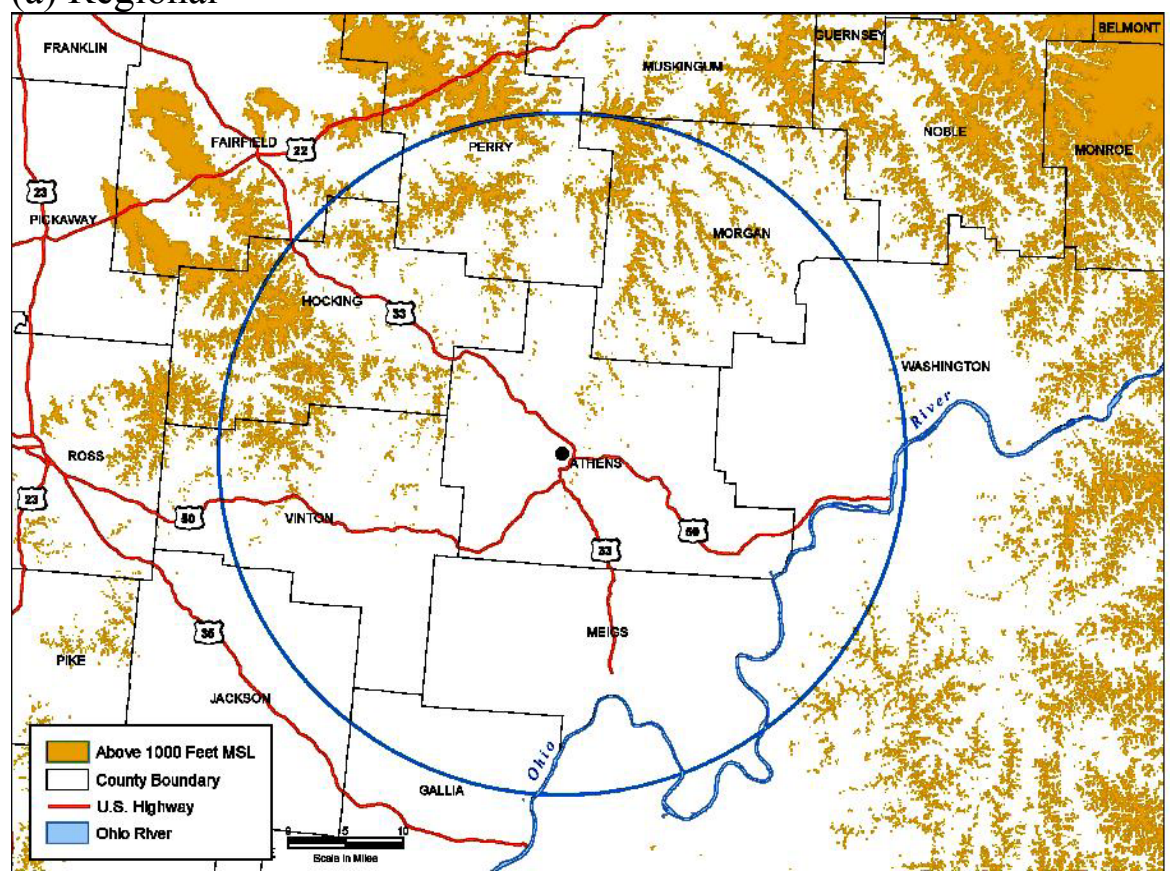

(b) Local

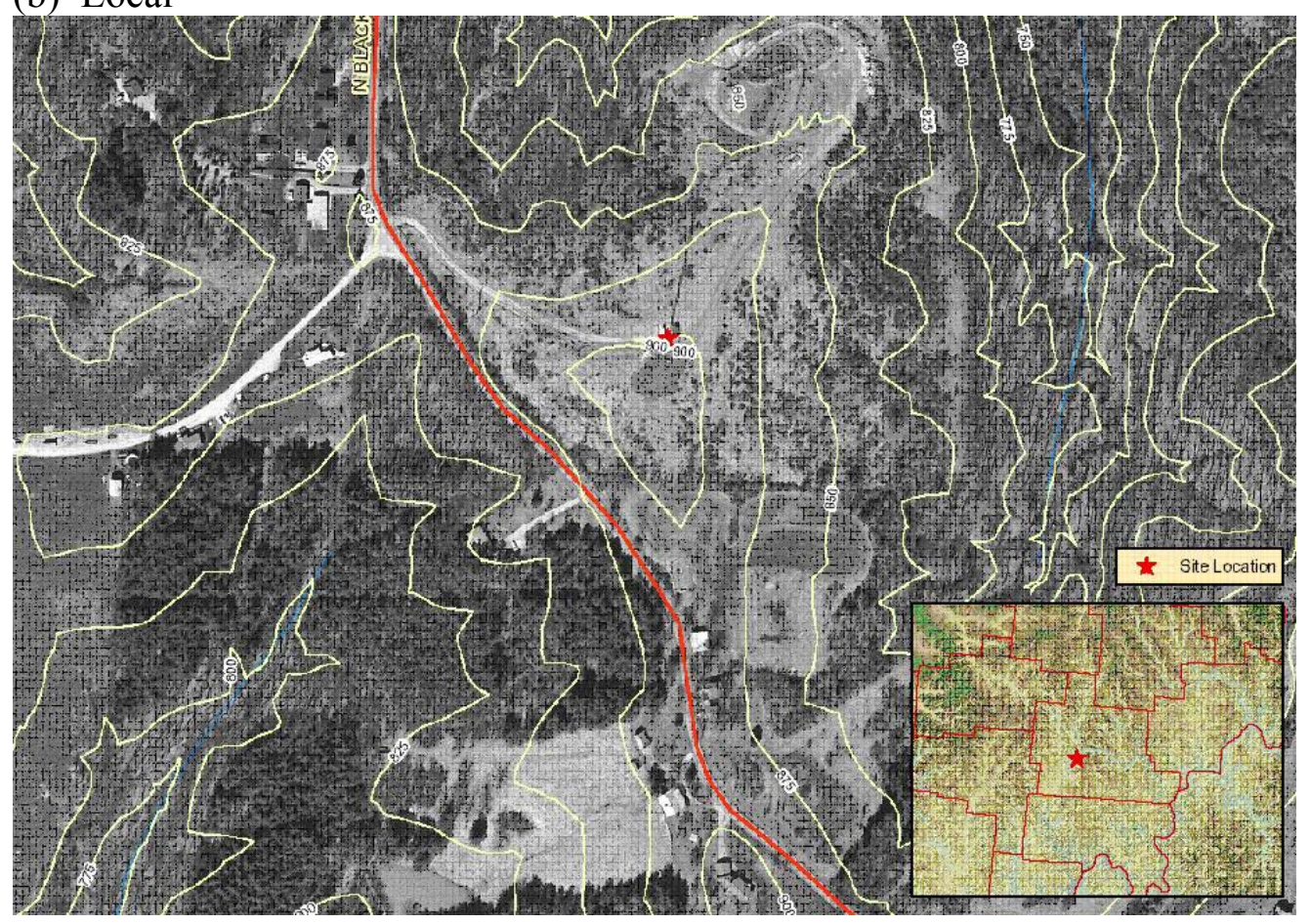

Figure 1. Topographical map of the Athens site: (a) regional and (b) local 
Task 1 accomplishments as of October 2, 2003:

CONSOL R\&D initiated start-up activities including procuring new equipment, repairing and maintaining existing sampling equipment, and making sampling arrangements, as outlined below:

- Placed the order for the Loda Electronics Mercury Wet Deposition Sampler August 8, 2003. The unit has not been received as of October 2, 2004.

- Placed the order for the Tekran Ambient Mercury Analyzer (including speciation, particulate modules, and vapor calibration source) on August 11, 2003.

- Placed the order for the Belfort Universal Rain Gauge on August 12, 2003. The unit has not been received as of October 2, 2004.

- Placed the order for the Tube Furnace on August 12, 2003. The unit has not been received as of October 2, 2004.

- Completed repairs and preventative maintenance to components of the monitoring trailer for the Steubenville Comprehensive Air Monitoring Program (SCAMP) (DOE Cooperative Agreement DE-FC26-OONT40771) that has been in storage since the end of May 2002, when the SCAMP sampling program ended. The components were the $\mathrm{SO}_{2}$, $\mathrm{O}_{3}, \mathrm{CO}$ and $\mathrm{NO}_{\mathrm{x}}$ ambient gas analyzers, data-logger, zero air generator, and E-DAS software. Cleaned the sampling manifold.

- Procured a four-gas EPA calibration standard to calibrate the trailer's gas analyzers on a daily basis. In addition, procured cylinders of trace argon and zero air for the Tekran ambient mercury system and denuder coating station, respectively.

- Sent a layout of the SCAMP trailer's electrical service to the Ohio University maintenance personnel in September 2003. The layout was necessary to secure the electrical permit for the site.

- Specified a new wind-direction vane component and a solar radiation cable for purchase. The existing units were damaged and not functional.

- Prepared a building permit and site plans for a monitoring site south of the campus on North Blackburn Road. Ohio University approved and secured the site. The building permit is currently under review by the county. The plans include the installation of a $10^{\prime}$ x $20^{\prime}$ deck 4 feet off the ground, a $10^{\prime}$ x $20^{\prime}$ environmentally controlled shed, and the SCAMP trailer. In addition, power installation at the site was initiated.

- Assembled the TEOM Series 1400a Ambient Particulate Monitor. For this study, an optional kit has been added which includes a Sample Equilibration System (SES) humidity unit, which will enable the system to operate at $30^{\circ} \mathrm{C}$.

The Athens site will utilize air-monitoring equipment from the NETL-sponsored SCAMP. In addition, the site will include sampling equipment to collect and measure mercury, including total, elemental, reactive, particulate, and wet/dry deposition. 
Total mercury will be measured using a Tekran Mercury Vapor Analyzer. This instrument is a real-time, continuous analyzer capable of measuring total mercury in the ambient air. The Tekran uses gold amalgamation coupled with cold-vapor atomic-fluorescence technology to measure ppt (by volume) concentrations of total mercury. In addition, the Tekran Mercury Vapor Analyzer will be equipped with the speciation and particulate modules that speciate the total mercury into elemental, reactive, and particulate concentrations. This will help to evaluate mercury concentrations attributed to the urban background or from fluxes due to industrial and geological sources in the Ohio Valley.

For studying wet deposition behavior of mercury, the research team will use an Aerochem Mercury Precipitation Collector identical to that being used by The National Ambient Mercury Deposition Network. Conversely, they will study dry deposition behavior of mercury through fine particulate collected on a Teflon filter with a $\mathrm{PM}_{2.5}$ Speciation Sampler operating on an every-third-day frequency. The particulate will be leached and measured using a cold vapor atomic absorption spectrometer configured with a gold amalgamation pre-concentration unit. Collection of these samples will add to our understanding about a number of issues associated with mercury deposition, including the potential impact on local water and eco-systems, reentrainment of mercury in the environment, and conversion of mercury to methyl mercury.

Utilizing equipment from SCAMP, the team will also collect fine particulate matter and arsenic using a Federal Reference Method $\mathrm{PM}_{2.5}$ filter-based sampler. The filter-based sampler will collect an integrated 24-hour particulate sample on an every-third-day frequency. The particulate on the filter will then be analyzed for mass and calculation of fine particulate matter concentration. The composition of the fine particulate matter will be measured through a combination of laboratory techniques including 1) elemental composition (including As) by inductively coupled plasma mass spectroscopy and 2) ions $\left(\mathrm{SO}_{4}{ }^{2-}, \mathrm{NO}_{3}{ }^{-}, \mathrm{Cl}^{-}, \mathrm{NH}_{4}{ }^{+}\right)$by ion chromatography. The $\mathrm{PM}_{2.5}$ speciation sampler, which will collect a particulate sample for mercury determination, will also be equipped to collect a quartz filter to be used to determine the carbon concentration of the particulate. Total as well as elemental and organic carbon concentration will be determined by analyzing the quartz filter with a thermal optical carbon aerosol analyzer. In addition to the filter-based fine particulate measurements, continuous gas analyzers and a 10 -meter weather station at the SAM will provide data to clarify how ambient pollutant concentrations $\left(\mathrm{SO}_{2}, \mathrm{NO}_{\mathrm{x}}, \mathrm{CO}, \mathrm{O}_{3}, \mathrm{THC}\right)$ and weather are associated with the formation of fine particulate. Project researchers will collect all sampling data from the site operator, check the data for $\mathrm{QA} / \mathrm{QC}$, and archive it into a common database for reduction, analysis, and modeling.

Task 2 - Evaluate and Select a 3-D Regional-Scale Atmospheric Chemical Transport Model (CTM) and Conduct a Base-Case Simulation

Several 3-D regional-scale CTMs with the ability to simulate tropospheric ozone, visibility, and fine particulate matter are appropriate for application to the Ohio River Valley Region to evaluate total fine particulate matter mass and the arsenic component of fine particulate matter. The ISEE and Atmospheric and Environmental Research (AER) have established the 3-D modeling framework. AER is conducting the base-case simulation. 
The project team chose the Community Multi-Scale Air Quality (CMAQ) model for air-pollution studies on a regional scale for this study. The EPA and its collaborators (Byun \& Ching, 1999) developed the CMAQ, which uses non-hydrostatic Penn State/NCAR mesoscale model (MM5)V3-derived dynamics for transport.

Task 2 accomplishments as of October 2, 2003:

- Received the Environmental Protection Agency (EPA) regional mesoscale modeling outputs (MM5) at grid resolution of $36 \mathrm{~km}$ for 1996 from the EPA on July 30, 2003 and processed with MCIP 2.2 to generate input meteorology files for CMAQ.

- Prepared seasonally and spatially varying boundary-condition (BC) files for the CMAQ simulations for the coarse grid domain (36-km resolution) based on $\mathrm{Hg}$ concentration output from AER's global model. Converted BCs for the gaseous $\mathrm{Hg}$ species from mass to ppmV units using CMAQ meteorological fields of temperatures and pressures for each season. Determined initial conditions (ICs) for each species from those used in AER's simulations with Electric Power Research Institute's (EPRI) Trace Elements Analysis Model (TEAM).

- Prepared input emission files for the coarse grid domain for CMAQ for January 1996, by adding the EPRI Hg emissions to the emission files provided by EPA. Identification of area sources involved mapping the TEAM grid (Polar Stereographic projection with 100$\mathrm{km}$ resolution) to the CMAQ grid (Lambert Conformal projection with 36-km resolution). For the point sources, an emissions processor similar to that used in SMOKE (Sparse Matrix Operator Kernel Emissions) modeling was used to calculate plume rise and distribute the point source $\mathrm{Hg}$ emissions vertically.

- Compiled the CMAQ-Hg code obtained from Dr. Russ Bullock at EPA and made a test simulation with the code after making appropriate modifications to the makefile. Also provided a sample meteorological input file to show the domain and projection for the coarse grid simulation.

- Initiated the annual simulation for the coarse grid domain with CMAQ-Hg. However, at initiation of the simulation, the code approximated real time so that the computer could compute only one hour of pollution data per run-time hour. This was impractical for computing data for the entire year. After some analysis, it was determined that the gasphase chemistry calculations required an inordinate amount of time. The version of CMAQ-Hg provided by EPA uses the SMVGEAR solver, which is highly accurate, but very slow, particularly on non-vector machines. The latest version of CMAQ uses the MEBI (Modified Euler Backward Iterative) solver, which is extremely fast as well as quite accurate. In a phone conversation, Dr. Bullock stated that the next version of CMAQ-Hg (not expected to be available until 2004) will also use the MEBI solver. Subsequently, the MEBI solver was implemented in the current version of CMAQ-Hg. This required some modifications to the MEBI solver code since the solver is mechanism and species dependent. The initial tests show a dramatic improvement (by about a factor of 6) in runtime with the MEBI solver. The results are being examined to make sure that they are consistent with those from the simulation using the SMVGEAR solver. 
- Began modifying the CMAQ-Hg code to calculate and save the daily cumulative dry and wet deposition amounts and daily average concentrations of $\mathrm{Hg}$ (the current model saves only the hourly values). This will assist in evaluating the model with long-term $\mathrm{Hg}$ deposition measurements from the Mercury Deposition Network (MDN).

- The project team at Ohio University has procured an 8-node Linux Cluster for running parallel implementations of the MM5 and CMAQ models. One main node, a RAID storage node, and seven compute nodes constitute the cluster, which provide a combined storage capacity of $2 \mathrm{~TB}$. Each of the compute nodes has dual $2.4 \mathrm{GHz}$ Pentium Xeon processors and $1 \mathrm{~GB}$ RAM. The main node has dual $2.4 \mathrm{GHz}$ processors and $3 \mathrm{~GB}$ RAM. The cluster is installed in a $42 \mathrm{U}$ rack and protected behind a secure firewall in a facility with redundant power supply provided by UPS (Uninterruptible Power Supply) units and a power generator. Apart from the Message Passing Interface software and the Portland Group Fortran and C Compilers, the cluster has several GNU open license and other scientific software. The main node doubles as a backup system, with the autoloader tape backup providing vital system configuration backup. This setup of the cluster provides an efficient and stable environment for running the modeling simulations.

Task 3 - Refine and Update Emission Inventories (EIs)

Advanced Technology Systems, Inc. (ATS) is enhancing the mercury and arsenic emission inventories.

Task 3 accomplishments as of October 2, 2003:

- On July 10, 2003, AER provided the EPRI mercury emissions data to Ohio University for use by ATS. ATS is evaluating and updating the data in the inventory in several stepsidentification and validation of original data source, developing a new emission database and gathering new data, and, finally, implementation of new data into the emission inventory framework for regional modeling.

- The mercury emission inventory prepared by AER used data by Pai et al (2000). The inventory covers the contiguous 48 states, southern Canada, and Northern Mexico. AER then compiled more current information for the United States using data provided by the EPA, EPRI, and Toxics Release Inventory (TRI). Data on Canadian sources was obtained from Canada's National Pollutant Release Inventory (NPRI) for that year and implemented into the database. Mexican data was scaled up using growth percentage estimated by the US DOE. ATS is evaluating the AER mercury emission inventory against the 1999 National Emission Inventory to identify discrepancies.

- ISEE team members initiated an ongoing literature survey of recent journals and publications identifying current accurate data or methods to improve the existing data set. Current articles suggest that, unless the data consists of direct measurements, reporting methods have resulted in a high level of uncertainty in existing databases. Emission factors have shown an even higher level of uncertainty for emissions reporting. Most reported data in current inventories is based upon emission factors; therefore, the researchers will utilize newer, more accurate emission factors for this project. CONSOL Energy recently authored an article about mercury emissions from coal-fired boilers. The 
article details the effectiveness of existing $\mathrm{SO}_{2}$ and $\mathrm{NO}_{\mathrm{x}}$ control systems of removing mercury from the flue gas streams of those boilers. These studies, sponsored by the Department of Energy, will be used to enhance the mercury emission inventory.

- Along with improving the data for mercury emissions, arsenic emissions in North America are being compiled. ATS has compiled a list of arsenic sources listed in the EPA's 2003 National Emissions Inventory. The 2002 NPRI, released in the fall of 2003, contained data for Canadian emissions of both mercury and arsenic. In addition, ATS is currently working to obtain updated emissions data on mercury from the Mexican National Ecology Institute and Energy Ministry.

\section{Task 4 - Perform Short-Period Model Runs for Comparison with Field Data}

ISEE will conduct a series of model runs to evaluate the system against field observations. First, the model will be set up along with an observational database for the Ohio Valley Region collected during the summer of 2001. The model run will correspond to the NETL-sponsored intensive sampling campaigns centered in Pittsburgh, Pennsylvania. Researchers will combine the extensive datasets collected during this campaign with other relevant datasets in this region. Meteorological input data for these simulations will be derived diagnostically using MM5 V3. The model evaluations will involve short-time-period runs for the field-intensive periods, storing hourly averaged fluxes and production-and-loss rates for ozone, hydrocarbons, arsenic, $\mathrm{Hg}^{0}$, and RGM for direct comparison with field data. In addition, long-range transport events will be identified from the short-term CTM runs and evaluated with the observational data set.

In addition to the model evaluations conducted from field observations obtained from the 2001 NETL-sponsored sampling campaigns, the model will be set up and evaluated against the observational data sets, including the speciated mercury and arsenic data collected at the Athens SAM for the 2004 sampling period. These simulations will be vital for model verification because the Athens SAM will be one of the few sites providing measurements on individual mercury species and arsenic. The model evaluations will involve short-time-period runs for the field-intensive periods, storing hourly averaged fluxes and production-and-loss rates for ozone, hydrocarbons, arsenic, $\mathrm{Hg}^{0}$, and RGM for direct comparison with field data. In addition, longrange transport events will be identified from the short-term CTM runs and evaluated with the observational data set.

The ISEE will perform the short-term model runs for comparison with field data.

Task 4 accomplishments as of October 2, 2003:

- Work is underway to perform regional and urban modeling simulations for 36-, 12-, and 4km-grid resolutions. The 36-km grid will cover most of Eastern United States, whereas the 4-km domain will cover all the power plants in the Ohio River Valley region.

- The current parallel version of MM5 has been downloaded to the system. Observational meteorological data sets are being acquired from the National Centers for Environmental Prediction (NCEP) to conduct 4DDA (four-dimensional data assimilation) as a part of MM5 simulations. 
- The latest version of the emissions model SMOKE has been downloaded to the system and compiled. It will be used to process the upgraded emission inventory prepared by ATS.

- ISEE staff has performed a benchmark run in the Linux cluster using AER's modified CMAQ-Hg code with the 1996 EPA MM5 outputs. Efforts are underway to prepare meteorological inputs to the photochemical model simulations on 12-km-grid and 4-km-grid resolutions.

\section{$\underline{\text { Task } 5 \text { - Seasonal Scale Simulations }}$}

A major focus of the modeling effort is to identify significant sources and source regions contributing to the deposition of mercury and ambient concentrations of arsenic and fine particulate matter. The modeling will also examine the efficacy of reduction strategies specifically for coal-fired power plants. In addition, researchers will conduct an analysis of the long-range transport from regions outside the Ohio Valley and the biospheric recycling of elemental $\mathrm{Hg}$ on the measured and modeled reactive and total mercury in the Ohio Valley Region.

Initially, researchers will set up a seasonal scale simulation for the entire North American continent on a coarse grid $(30 \mathrm{~km} \times 30 \mathrm{~km})$, with a nested grid of $10 \mathrm{~km}$ over the midwestern region of the United States and $3.3 \mathrm{~km}$ over the Ohio Valley Region. They will use the NCEP4D assimilation data set to drive the regional-scale meteorology model (MM5 V3) to develop dynamic inputs for the CTM. The model analysis will be completed for the seasonal run to establish a 'base-case' simulation or the most likely current-day simulation for the season. Uncertainty ranges will be developed for critical parameters in the model, such as emissions and deposition rates. Additional seasonal scale simulations will be performed to develop an 'uncertainty envelope' of the model-generated estimates of deposition rates and fluxes.

Task 5 accomplishments as of October 2, 2003:

- The project staff has completed no work on this task, slated for a later phase of the project.

\section{$\underline{\text { Task } 6 \text { - Development of a Decision-Support Tool }}$}

ISEE will conduct a series of model runs to perform a matrix analysis of the sensitivity of point sources to deposition patterns in the region. The analysis will also include selective emission reduction scenarios for these point sources. The team will couple this matrix with a GIS and the emission pre-processor to provide a detailed spatial analysis of the source-receptor relationships. In addition, this entire system will be supported by Web-based technologies to provide industry and government agencies with a user-friendly decision-support tool that will evaluate sourcereceptor relationships and the efficacy of emission reduction strategies.

- The project staff has completed no work on this task, slated for a later phase of the project. 


\section{Task 7 - Project Management, Data Analysis, and Reporting}

This task involves all communication between the project team members, DOE-NETL, and external collaborating parties and includes all meetings, presentations, and DOE-required reports pertaining to the project. To facilitate data analysis, the data from the SAM and the results of the model runs will be archived into a user-friendly database that will provide functionality to help calculate final mercury, arsenic, and fine particulate matter mass and composition concentrations. It will also allow the delineation of basic trends and the evaluation of variables. To the greatest extent possible, the data from the SAM site will be incorporated into the ambient air quality database being compiled for DOE-NETL by ATS and Ohio University under project DE-FC26-02NT41476. However, the primary function of the database will be to reduce data efficiently for evaluation of the proposed model simulations. At the conclusion of the project, Ohio University will submit the database containing the SAM information, results of model runs, and comparison statistics to DOE-NETL along with a comprehensive final report.

Task 7 accomplishments as of October 2, 2003:

- A kickoff meeting for the project was held May 13, 2003 at the NETL facility in Pittsburgh. The kickoff meeting utilized a webcast presentation and involved state, federal, and industry representatives who have an interest in the project. The meeting involved an overview of the project, including a detailed description of the project tasks.

\section{RESULTS AND DISCUSSION}

Contract negotiations with the subcontractors delayed the first phase of this project by approximately three months. However, during the first six months of the project (April 3, 2003October 2, 2003), the university established the SAM site at Athens, Ohio. Within the next three months (October-December 2003), the SAM site will be operational. The SAM site's official start date is late February or early March of 2004.

The ISEE researchers chose the CMAQ model developed for air-pollution studies on a regional scale by the EPA and its collaborators. AER is currently preparing the boundary conditions and the input emission files for the 36-km-grid domain for 1996. The target date for the initiation of the annual simulation for the coarse grid domain is November 30, 2003.

ATS is currently upgrading the mercury and arsenic emission inventory files. The focus of their efforts is to develop a comprehensive and accurate emission inventory utilizing current research on emissions data from coal-fired power plants. The ISEE has initiated work on the seasonal scale simulations for 2001 and 2004. Researchers will utilize these simulations to evaluate the system against field observations. Within the next several months, they will develop parallel implementations of MM5 and CMAQ for the seasonal scale simulations.

\section{CONCLUSIONS}

The initial phase of the project was delayed by approximately three months due to contract negotiations with the subcontractors. However, the monitoring efforts and the modeling efforts have been initiated and are proceeding as expected. 


\section{REFERENCES}

Byun, D. and J. Ching, 1999: Introduction to the Models-3 framework and the Community Multiscale Air Quality Model (CMAQ). In Science Algorithms of the EPA Models-3 Community Multiscale Air Quality (CMAQ) Modeling System, EPA/600/R-99/030, U.S. Environmental Protection Agency, Washington, D.C

Pai, P., D. Niemi, and B. Powers, A North American inventory of anthropogenic mercury emissions. Fuel Processing Technology, 65-66, 101-115, 2000. 